Bases biológicas dos transtornos psiquiátricos Flávio Kapczinski, João Quevedo e Iván Izquierdo e colaboradores. Porto Alegre: Artmed, 2004,503 páginas. $2^{\mathrm{a}}$ edição. ISBN 85-363-0283-6.

The breakthrough related to the biological foundations of mental disorders in the last ten years hampers psychiatrists to learn, organize and synthesize the information, as to develop a comprehensive and integrated view of this field of knowledge. This task will be enormously facilitated for those who would dedicate themselves to the reading of the second edition

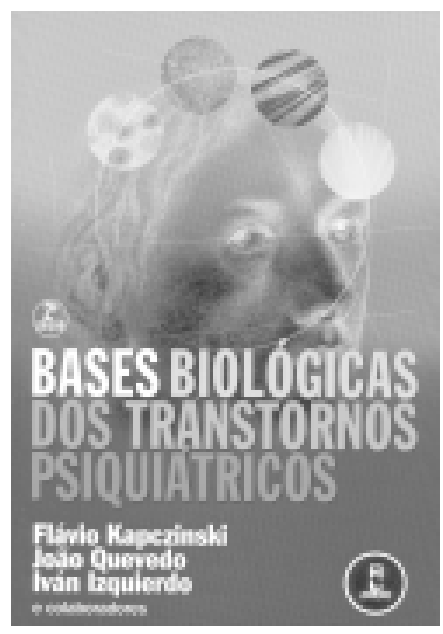
of 'Biological foundations of psychiatric disorders'. These renowned authors accomplished the Herculean task of transmitting these updated knowledge in a didactic way. Modestly, they have admitted that any attempt of systematization in this area would be incomplete. They managed, however, to reflect the progress in the major areas which constitute the current biological psychiatry.

The text is structured in five sections: 1) The central nervous system; 2) Neuropsychological assessment; 3) Biological treatments; 4) Psychiatric disorders and; 5) New developments.

In the first session, the authors deal extensively and comprehensively with the biological foundations of the central nervous system. Subjects such as the neuron, neurotransmitters, neuroanatomy, neuroplasticity, psychoneuroendocrinology, psychoimmunology, neurotoxicology, genetics and animal models of mental disorders are didactically and elegantly presented, making the reading not only informative, but also quite pleasant. However, the careful reader will occasionally feel the absence of the description of the neuroplastic mechanisms related with the kindling biological model, which is important for the description of the neuropsychiatric phenomena that are possibly associated with epilepsies, but that are also considered for bipolar disorders and substance dependence.

In the second section, the instruments for neuropsychological and neuroimaging investigation are presented. In the chapter on neuroimaging, the methods of structural and functional imaging are discussed.

The third section explores the foundations of psychopharmacological and electroconvulsive therapies. We felt the absence of a chapter on psychosurgery, a still polemic issue in psychiatry, but which is an important source for the biological foundations of some mental disorders.

In the fourth section, the authors summarize the most important information regarding the biological foundations of the most important mental disorders. The approach is predominantly theoretical and the psychopathological and/or clinical aspects are described only to lay the foundations of the biological approach. Nevertheless, the authors, in general, do not fall into biological reductionism.

Special efforts for the development of an integrating view can be observed, such as the chapters on obsessive-compulsive disorder and impulsivity. The approach in this section is somewhat unbalanced regarding the presentation of mental problems of neuropsychiatric disorders: although the mechanisms involved in the epileptogenesis in the chapter on epilepsies are brilliantly presented, the authors do not mention neither the frequent and important mental disorders associated with this neuropsychiatric condition, nor their biological mechanisms, what does not happen in the chapter on Parkinson's disease. This fact does not reduce the brilliantness of these presentations.

According to the authors, the last section - in which the role of phospholipase A2, adenosine, prion, protein S $100 \beta$ and oxidative stress in mental disorders are described - was destined to transmit the idea that there is a permanent progress in this area and that any treatise on the subject is equivalent to a picture of a moving object. Surely, a nice picture.

We must, therefore, celebrate the arrival of 'Biological foundations of psychiatric disorders', enjoy its reading or consultation and only wait for the next edition.

Renato Luiz Marchetti Institute and Department of Psychiatry of the Clinical Hospital of the Medical School of the University of São Paulo

\section{Vencendo o transtorno obsessivo-compulsivo: manual da terapia cognitivo-comportamental para pacientes e terapeutas}

Aristides Volpato Cordioli. Porto Alegre: Artmed, 2004, 166 páginas. ISBN 85-363-0284-4.

In the last years, we had an increasing interest in the media and in the public opinion on issues related to obsessivecompulsive disorders (OCD). This increase is partially due to the unremitting efforts of associations of patients and to the courage of famous people in disclosing in public their stories due to the disease. The endeavor of researchers in this area was the other important part to make the scientific

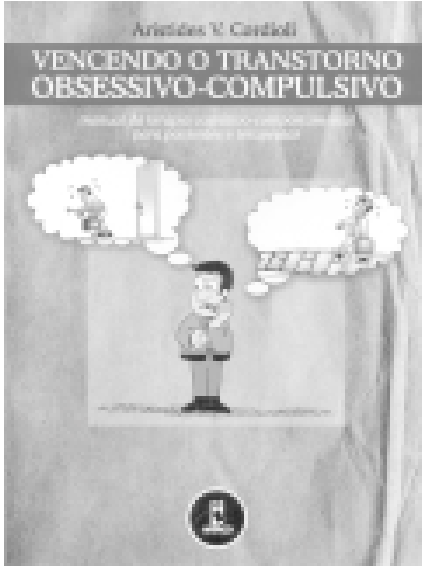


progress available for the lay public, both regarding the medical investigation and the behavioral and cognitive therapies.

This book is an excellent example of this last group. The author presents in a precise, detailed, and simple way, the basic information on OCD, its probable origins and, especially, the behavioral and cognitive strategies aimed to manage the issues related to this diagnosis.

Twelve chapters compose the work, each of them representing a section of a cognitive-behavioral program.

Sections 1 to 5 follow the characteristic stages of this kind of program, including the initial assessment and the information about the disorder (sections 1 and 2), explanations about the technique of exposure with response prevention and its application for each kind of obsessive-compulsive behavior (sections 3 and 4 ) and presentation of the cognitive strategies (section 5).

In sections 6 to 9 the book unfolds its highest merit: the clear and detailed description of the specificities in the treatment of each of the main groups of obsessive-compulsive symptoms (contamination obsessions - 6; hyper-responsibility - 7; obsessions of improper content - 8; perfectionism - 9). These four 'sections' by themselves would justify the edition of the book, as until now no work in Brazil has brought this contribution.

Section 10 discusses the impact of OCD on the family and its role in the maintenance of the problem, as well as its overcoming, whereas sections 11 to 14 (chapter 11) deal with the treatment's continuity.

Lastly, section 15 presents aspects related to discharge and prevention of relapses.

The book has also some basic information on drug treatment and some symptom-assessing scales and self-monitoring spreadsheets.
Considering all the qualities of the book, it is worth highlighting one aspect that deserves being discussed: the author presents the cognitive-behavioral therapy as 'brief therapy, performed, mostly, in 10 to 15 sections'. Afterwards, the author states that it 'has a short duration and is symptom-focused'. This kind of presentation only reinforces the generalized prejudice that behavioral therapy is limited to a set of symptom-relieving procedures and that, in case patients want a deeper work, they need to seek other psychotherapic approaches. Unfortunately, the author is accompanied by great part of the cognitive-behavioral literature in the divulging of this prejudice.

Nevertheless, what in this book is called cognitive-behavioral therapy corresponds only to a set of techniques (very efficient, by the way), aimed at solving a specific problem. In other words, they are strategies derived from cognitive-behavioral therapy, but not the cognitive-behavioral therapy. This attitude perhaps justifies the author's recommendations (p. 34) about when one must seek this type of therapy ('if the symptoms are severe enough or if you are not sufficiently disciplined to perform the exercises alone'). Borrowing an analogy used by Banaco ${ }^{1}$ (1999) ' art is being confused with the procedures it utilizes'. Although this may seem a simple question of denomination, it regards to the role assumed by the professional: that of a mere technician which removes symptoms or someone who can offer full therapeutical support to a suffering person.

Denis Roberto Zamignani Post-graduation Program in Clinical Psychology at the University of São Paulo

\section{Reference}

1. Banaco RA. Técnicas cognitivo-comportamentais e análise funcional. In: Kerbauy RR, Wielenska RC, orgs. Psicologia comportamental e cognitiva: da reflexão teórica à diversidade na aplicação. Santo André: ARBytes; 1999. vol. 4. p. 75-82. 